\title{
Permanent Magnet Absorbed Repairing End Effector for Wall-Climbing Robot
}

\author{
Z.W. Cui,Z.G. Sun, W.Z. Zhang \\ Department of Mechanical Engineering \\ Tsinghua University \\ Beijing, China
}

\author{
Q. Chen \\ Department of Mechanical Engineering \\ Tsinghua University \\ Beijing, China \\ Yangtze Delta Region Institute of Tsinghua University \\ Jiaxing, China
}

\begin{abstract}
In order to fulfil all-position amending of weld seam with wall-climbing robot, a permanent magnet adsorbed repairing end effector (REE) is developed. Cutting tool is installed in atwo-dimensional (2D) cutting force mode to decrease the driving force ofthemanipulator. A permanent magnet adsorption supporting apparatus (PMASA) is specially designed, so as to achieve reliable adsorption and flexible movement on complex curved surface. Both lifting and rotatingofthecutting tool are realized separately. The end effector is $\Phi 274 \mathrm{~mm} \times 240 \mathrm{~mm}$ in sizeand less than $10 \mathrm{~kg}$ in weight. Integrated withawall-climbing robot, the REEcouldperform all-position repairing works on the complex curved surface of steel structures, whose curvature radius is above $1.5 \mathrm{~m}$.
\end{abstract}

Keywords-end effector; wall-climbing robot; all-position operation; magnetic adsorption; complex curved surface

\section{INTRODUCTION}

Currently, most construction andmaintenance works of the main components of large hydropower stations, such as penstock, spiral case, turbine runner and so on, are carried out manually.Some kinds of wall-climbing robots were developed to replace the roles of human being, to fulfil welding, amending and cleaning. So far, the Scompirobot [1], which is a rail-guided, six-axis, multi-process robot, is the only one having been utilized to repair hydraulic turbine blades. The rail has to be installed and demounted repeatedly according to damagedpositions. In contrast, featuring the advantages of cost and time saving, rail-free permanentmagnetic absorbed wallclimbing robots (PMAWRs) can move freely on the surface of some ferromagnetic workpieces [2].

Traditional PMAWRs are consisted of a magnetic absorbed mobile platform and a cantilever manipulator, as shown in Fig.1(a). Equipped with the end effectors like CCD camera, welding torch, these robots can fulfiltasks like visualinspection, surface cleaning ordepositwelding [3].However, when the robot is used to do all-position amending or machining of weld seam,problems of overturning and insufficientstiffness (especially stiffness in direction normal to workpiece surface) may occur. To solve thoseproblems, novelPMAWR, whosemobile platform and repairing end effector are adsorbed to theworkpiece with permanent magnets [4], was developed, as shown in Fig. 1(b). The anti-overturning ability and stiffness of wall-climbing robotsaregreatly enhanced, since the mobile platform, manipulator, repairing end effector and workpieceform a closed structure together.
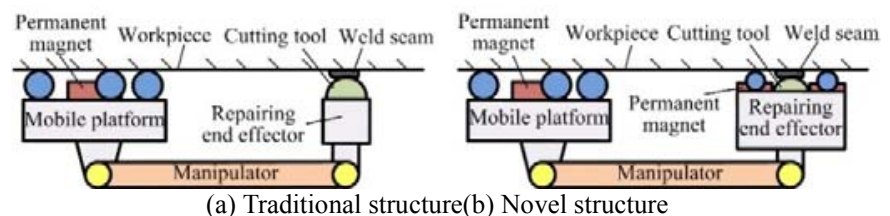

(a) Traditional structure(b) Novel structure

FIGURE I. DIFFERENT STRUCTURES OF PMAWRS

In this paper, repairing endeffector (REE) with permanent magnet adsorption units for PMAWRwas designed and prototypal produced.

\section{REQUIREMENTS FOR REE}

In order to accomplishall-position repairing on complex curved surface of large steel structures like hydraulic turbine runner, spiral case and so on, requirements for the REE are listed as follows:

(1) Installation mode of thecutting tool should reduce required driving force of the REE, so as to reduce stiffness requirement and power consumption for manipulator. The cutting tool can be lifted and rotated to carry out repairing operations.

(2)The REEshould be reliably adsorbed andflexiblymovedonworkpiecesurface in all positions.

(3) Curvature changes of the workpiece should be adapted.

(4) Maximumheightshouldbe less than $390 \mathrm{~mm}$, and whole weight should beno more than $10 \mathrm{~kg}$.

\section{INSTALLATION MODES OF THE CUTTING TOOL}

\section{A. Installation Modes of the Cutting Tool}

As shown in Fig.2, the cutting tool is installed to amend a weld seam along the feed direction $v_{\mathrm{f}}$, which is parallel to the weld seam direction. Coordinate system $\mathrm{O}_{0}-\mathrm{X}_{0} \mathrm{Y}_{0} \mathrm{Z}_{0}$ is established, where $\mathrm{O}_{0}$ is placed in the center of cutting tool, $\mathrm{X}_{0}$ axis is parallel totheweld seam, $\mathrm{Z}_{0}$ axis is normal to the workpiece surface. $F_{\mathrm{a}}, F_{\mathrm{t}}$ and $F_{\mathrm{r}}$ denote the cutting force along the axial, tangential andradialdirectionsof cutting tool respectively. $\theta_{\mathrm{c}}$ is the angle between the directionofweld seam and the central axis of cutting tool. $F_{\mathrm{a}}, F_{\mathrm{t}}$ and $F_{\mathrm{r}}$ can be decomposed into $\mathrm{X}_{0}, \mathrm{Y}_{0}$ and $\mathrm{Z}_{0}$ directions, which are, $F_{\mathrm{x} 0}, F_{\mathrm{y} 0}$ and $F_{\mathrm{z} 0} \cdot F_{\mathrm{n}}$ denotes the cutting force along the normal direction 
of workpiece surface, which is the resultant force of $F_{\mathrm{a}}, F_{\mathrm{t}}$ and $F_{\mathrm{r}}$ in $\mathrm{Z}_{0}$ direction. According to relative position between the cutting tool and workpice/weld seam, the cutting forces on the cutting tool can be classified into three cases:

Case 1 is shown in Fig. 2(a): the centralaxis of the cutting tool is vertical to the surface of workpiece[5]. The cutting forces in case 1 include $F_{\mathrm{a}}$ (also is $\left.F_{\mathrm{n}}\right), F_{\mathrm{t}}$ and $F_{\mathrm{r}}$.

Case 2 is shown in Fig. 2(b): $\theta_{\mathrm{c}}$ is an acute angle [1]. Cutting forces in case 2 include $F_{\mathrm{a}}, F_{\mathrm{t}}$ and $F_{\mathrm{r}}$. In case 1 and 2, The cutting tool is sufferingthree-dimensional (3D)cutting forces, where $F_{\mathrm{x} 0} \neq 0, F_{\mathrm{y} 0} \neq 0$ and $F_{\mathrm{z} 0}\left(\right.$ also is $\left.F_{\mathrm{n}}\right) \neq 0$.

Case 3 is shown in Fig. 2(c): the central axis of the cutting tool is parallel tothe surface of workpiece. When $F_{\mathrm{a}}=0$, the cutting forces on cutting toolare $F_{\mathrm{r}}\left(\right.$ also is $\left.F_{\mathrm{n}}\right)$ and $F_{\mathrm{t}}$, where the cutting tool is suffering two-dimensional (2D) cutting force. That means $F_{\mathrm{z} 0}\left(\right.$ also is $\left.F_{\mathrm{n}}\right) \neq 0, F_{\mathrm{x} 0}\left(\right.$ also is $\left.F_{\mathrm{t}}\right) \neq 0$, whereas $F_{\mathrm{y} 0}=0$.

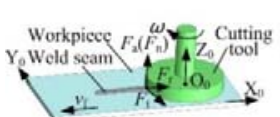

(a) Case 1

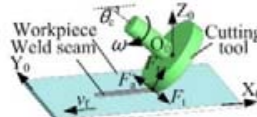

(b) Case 2

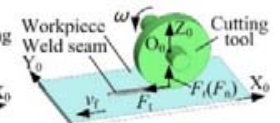

(b) Case 3
FIGURE II. THE CUTTING FORCES ON A CUTTING TOOL WITH DIFFERENT MODES.

Since the cutting tool is fixed onthe REE, the cutting forces acting on the cutting tool are also acting onthe REE. Forces acting on REE in $3 \mathrm{D}$ or $2 \mathrm{D}$ cutting force mode are shown in Fig.3(a) and Fig.3(b). Coordinate system O-XYZ is established, where origin point $\mathrm{O}$ is placed at the cutting point, $\mathrm{Z}$ axis is normal to the local workpiece surface, $\mathrm{X}$ axis is parallel to the horizontal plane; $\theta$ is the angle between the local workpiece surface and horizontal planewhich is ranged in $[0, \pi], F_{\mathrm{m}}$ is the adsorptive force imposed on the REE by workpiece, $G_{e}$ is the gravity of the REE, $G_{m}$ is the gravity of the manipulator, $M_{\mathrm{z}}$ denotes the driving torque along $\mathrm{Z}$ direction acting on the REE by the manipulator, $F_{\mathrm{p}}$ is the driving force on XOY plane acting on the REE by the manipulator, $F_{\mathrm{x}}$ and $F_{\mathrm{y}}$ arethecomponent forces of $F_{\mathrm{p}}$ in $\mathrm{X}$ direction and $\mathrm{Y}$ direction respectively, $N_{\mathrm{i}}(\mathrm{i}=1,2,3)$ is the supporting force acting on wheel $\mathrm{P}_{\mathrm{i}}$ bythe workpiece, $F_{\mathrm{f}}$ is the friction force acting on the REE by the workpiece; $R$ is the radius of the circle that wheels $\mathrm{P}_{1}, \mathrm{P}_{2}$ and $\mathrm{P}_{3}$ are placed in, $\theta_{\mathrm{f}}$ represents the angle between $v_{\mathrm{f}}$ and $\mathrm{X}$ axis ranged in $[0,2 \pi) ; \beta$ represents the angle between $v_{\mathrm{f}}$ and line $\mathrm{OP}_{1}$ ranged in $[0,2 \pi)$; $\mathrm{H}_{\mathrm{e}}$ is the distance between workpiece and the centerof gravity $\mathrm{O}_{\mathrm{e}}$ ofthe REE; $\mathrm{H}_{\mathrm{m}}$ is the distance from the connection joint $\mathrm{O}_{\mathrm{m}}$ between manipulator and the REE to workpiece.

As illustrated in Fig.3, when the wall-climbing robot is performing task in some given positions such as overhead repairing, $F_{\mathrm{m}}$ can balance out $F_{\mathrm{n}}$ and overcometheeffects of $\mathrm{G}_{\mathrm{e}}$ and $\mathrm{G}_{\mathrm{m}} / 2$, so as to decrease the overturning moment of the robot. Meanwhile, stiffnessrequirements parallel to workpiece surface for manipulator can also be greatly reduced. Secondly, $F_{\mathrm{x} 0}$ can balance out $F_{\mathrm{f}}$ partly, or even becomes driving force for REE by down-cutting (just like downgrinding), since $F_{\mathrm{x} 0}$ is parallel to $v_{\mathrm{f}}$, so as to reduce $F_{\mathrm{p}}$. Finally; in the case of $2 \mathrm{D}$ cutting force mode, $F_{\mathrm{y} 0}=0$ will lower $F_{\mathrm{p}}$ further, thus stiffness requirement and power consumption parallel to workpiece surface for the manipulator may be decreased.Besides, 2D cutting force mode may do favour tosimplifythe control of the robot.

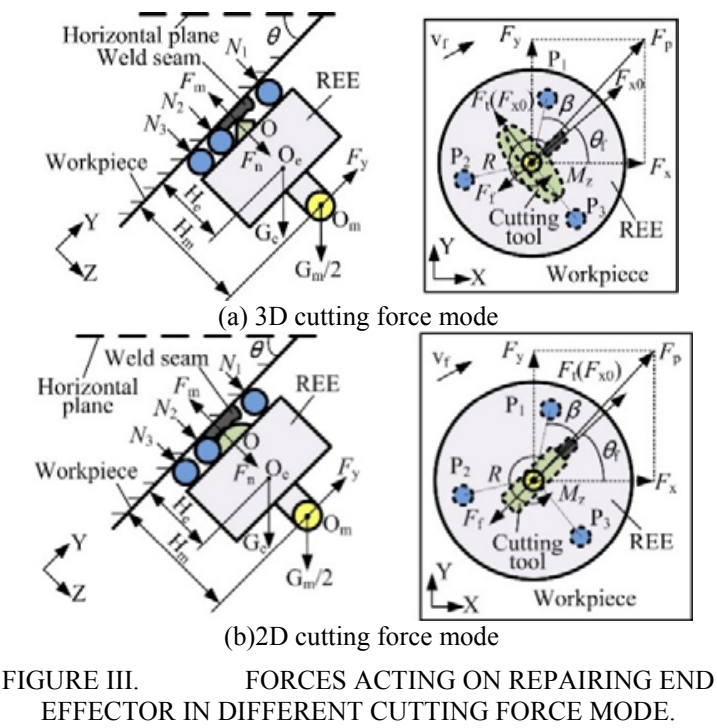

In next part,only $F_{\mathrm{p}}$ in $3 \mathrm{D}$ cutting force mode, and 2D cutting force mode is calculated and compared because $F_{\mathrm{p}}$ has much higher stiffness requirement and power consumption for manipulator than $M_{\mathrm{z}} . F_{\mathrm{a}}$ is commonly much smaller than $F_{\mathrm{t}}$ and $F_{\mathrm{r}}$, thus $F_{\mathrm{a}}$ can be neglected.

\section{B. Driving force in 3D Cutting Force Mode}

In Figs. 2(a), 2(b) and 3(a), cutting tool is in 3D cutting force mode. Maximum of $F_{\mathrm{p}}$ is deduced as follows:

$$
F_{\mathrm{p}}=\sqrt{F_{\mathrm{x}}{ }^{2}+F_{\mathrm{y}}{ }^{2}} \leq \sqrt{\left.\int\left[F_{\mathrm{m}}-\left(\mathrm{G}_{\mathrm{e}}+\frac{\mathrm{G}_{\mathrm{m}}}{2}\right) \cos \theta\right] \mu_{\mathrm{d}}+F_{\mathrm{r}} \sqrt{\mu_{\mathrm{d}}{ }^{2}+1}\right\}^{2}+F_{\mathrm{t}}^{2}}+\left(\mathrm{G}_{\mathrm{e}}+\frac{\mathrm{G}_{\mathrm{m}}}{2}\right) \sin \theta .
$$

where $\mu_{\mathrm{d}}$ is dynamic friction coefficient between REE and workpiece.

\section{Driving Force in 2D Cutting Force Mode}

Maximum of $F_{\mathrm{p}}$ in 2D cutting force mode as shown in Figs. 2(c), 2(d) and 3(b) is derived as:

$$
F_{\mathrm{p}}=\sqrt{F_{\mathrm{x}}^{2}+F_{\mathrm{y}}^{2}} \leq \sqrt{\left\{\left[F_{\mathrm{m}}-\left(\mathrm{G}_{\mathrm{e}}+\frac{\mathrm{G}_{\mathrm{m}}}{2}\right) \cos \theta\right] \mu_{\mathrm{d}}-\left(F_{\mathrm{r}} \mu_{\mathrm{d}}+F_{\mathrm{t}}\right)\right\}^{2}}+\left(\mathrm{G}_{\mathrm{c}}+\frac{\mathrm{G}_{\mathrm{m}}}{2}\right) \sin \theta .
$$

By comparing Eq.(1) with Eq.(2), the following conclusion can be drawn: $F_{\mathrm{p}}$ in $2 \mathrm{D}$ cutting force mode is smaller. That is to say, the installation manner of cutting tool in Fig.2(c) can lower driving force, thus reducing stiffness requirement and power consumption for manipulator.

\section{STRUCTURE DESIGN OF PERMANENT MAGNET ADSORPTION SUPPORTING APPARATUS}

In order to reach the needs of reliable adsorption, flexible movement and autonomousadaptation of curved surface, a permanent magnet adsorption supporting apparatus(PMASA) equipped at the bottom of the REE is specially designed, as shown in Fig. 4. The PMASA is composed of a chassis (1), 
three permanent magnetdevices (PMADs) (2) and three ball transfer units (BTUs) (3).

Each PMAD contains one yoke iron (4), N pole (5) and S pole (6). Every PMAD contacts with workpiece through a BTU, which means, an air gap $\delta$ exists between the PMAD and workpiece surface. BTUs are made with non-magnetic material. The BTU guarantees the air gap. Each PMAD, air gap and steel workpiece constitutes a magnetic circuit to offer adsorptive force. The change of adsorptive force could also be reduced when PMASA is moving on complex curved surface.

Employing the three BTUs, the PMASA could contact with workpiece steadily, adapt to curvature change of workpiece, and move flexibly on workpiece surface. These BTUs are placed in a regular triangle form, and center of the regular triangle is coincident with cutting point, so that REE is evenly forced. LineoftwoBTUs is vertical to the axis of cutting tool to realize 2D cutting force mode and avoid space interference.

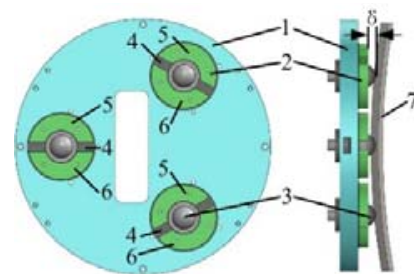

1-chassis; 2-PMAD; 3-BTU; 4-yoke iron; 5-N pole of PMAD; 6-S pole of PMAD; 7-workpiece

FIGURE IV. STRUCTURE ILLUSTRATION OF THEPMASA.

The conditions that the REE can be adsorbed to workpiece reliably without falling off or overturning are:

$$
\begin{aligned}
& R>2 \mu_{\mathrm{d}} \mathrm{H}_{\mathrm{m}} \\
& F_{\mathrm{m}}>F_{\mathrm{n}}+\max \left\{\begin{array}{l}
\frac{\sqrt{3} \mathrm{~F}_{\mathrm{t}} \mathrm{H}_{\mathrm{m}}}{R+\sqrt{3} \mu_{\mathrm{d}} \mathrm{H}_{\mathrm{m}}}+\sqrt{\frac{4 \mathrm{G}_{\mathrm{c}}{ }^{2}\left(\mathrm{H}_{\mathrm{m}}-\mathrm{H}_{\mathrm{c}}\right)^{2}}{\left(R+\sqrt{3} \mu_{\mathrm{d}} \mathrm{H}_{\mathrm{m}}\right)^{2}}+\left(\mathrm{G}_{\mathrm{c}}+\frac{\mathrm{G}_{\mathrm{m}}}{2}\right)^{2}}, \\
\frac{-\sqrt{3} F_{\mathrm{H}} \mathrm{H}_{\mathrm{m}}}{R-\sqrt{3} \mu_{\mathrm{d}} \mathrm{H}_{\mathrm{m}}}+\sqrt{\frac{4 \mathrm{G}_{\mathrm{c}}{ }^{2}\left(\mathrm{H}_{\mathrm{m}}-\mathrm{H}_{\mathrm{c}}\right)^{2}}{\left(R-\sqrt{3} \mu_{\mathrm{d}} \mathrm{H}_{\mathrm{m}}\right)^{2}}+\left(\mathrm{G}_{\mathrm{c}}+\frac{\mathrm{G}_{\mathrm{m}}}{2}\right)^{2}}, \sqrt{\frac{4 \mathrm{G}_{\mathrm{c}}{ }^{2}\left(\mathrm{H}_{\mathrm{a}}-\mathrm{H}_{\mathrm{m}}\right)^{2}}{R^{2}}+\left(\mathrm{G}_{\mathrm{c}}+\frac{\mathrm{G}_{\mathrm{m}}}{2}\right)^{2}}
\end{array}\right\} .
\end{aligned}
$$

\section{PROTOTYPICAL PRODUCE OF THE REE WITH PMASA}

Fixing the cutting tool in $2 \mathrm{D}$ cutting force mode, and integrating the specially designed PMASA, a permanent magnet adsorbed REE is designed andprototypeicallyproduced, as shown in Fig.5.
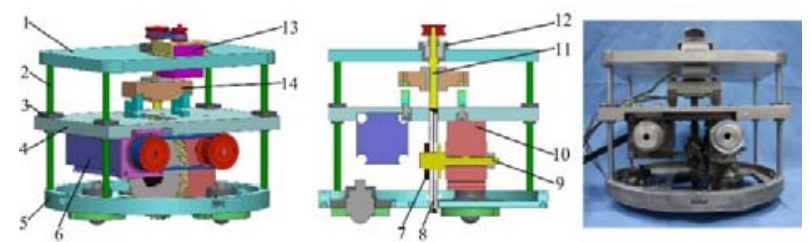

(a) Isometric view(b) Section view(c) Prototype

1-top frame;2-linear shaft; 3-linear bushing; 4-middle frame; 5-PMASA; 6-motor for cutting tool rotating; 7-clamping nut; 8-cutting tool; 9-spindle;

10-gearbox;11-ball screw;12-support unit; 13- motor for cutting tool lifting; 14-connection frame

FIGURE V. FIGURE5:PERMANENT MAGNET ADSORBED REE WITH PMASA.
Frameworks includestop frame (1), linear shaft (2), linear bushing (3), middle frame (4) and PMASA (5), aiming to guarantee reliable adsorption and flexible movement for the REE.

Motor for cutting tool rotating (6), clamping nut (7), cutting tool (8), spindle (9), gearbox (10) and so on are installed below middle frame to realize function of weld repairing. The motor and gearbox are located on two sides of cutting toolto lower the distance He between workpieceand the centerof gravity ofthe REE. The center of gravity of the parts (6)-(10) locates on normal line ofthe repairing end effector approximately. Spindle and output shaft of gearbox are made as a whole, to simplify transmission mechanism.

Ball screw (11), support unit (12), motor for cutting tool lifting (13), connection frame (14) are applied to drive middle frame to do up/down motion to achieve lifting for cutting tool.Stepper motor is selected for lifting motor to control displacement precisely.

In reference to the new machining method [6] with advantages of small cutting forces and high efficiency, cutting forces and processing parameters are designed as follows: $F_{\mathrm{n}}=100 \mathrm{~N} ; F_{\mathrm{t}}=60 \mathrm{~N}$; cutting speed is about $4 \mathrm{~m} / \mathrm{s}$. By calculation using Eqs. (3) and (4), $F_{\mathrm{m}}=450 \mathrm{Nand} R=86.6 \mathrm{~mm}$ are designed. Power of cutting motor is $250 \mathrm{~W}$, and lifting distance of cutting tool is $-2.5 \sim 5.5 \mathrm{~mm}$, where negative value meansthat cutting point is below the contact surface of the REE and the workpiece.

Main parameters of the prototypical REE are listed in Table 1.

\begin{tabular}{ll} 
TABLE I. & MAIN PARAMETERS OF THE PROTOTYPICAL REE. \\
\hline Parameters & Values \\
\hline Whole size $($ diameter $\mathrm{mm} \times$ height $\mathrm{mm})$ & $\Phi 274 \times 240$ \\
Whole weight $(\mathrm{kg})$ & About 10 \\
Curvature radius adapted to $(\mathrm{m})$ & $\geq 1.5$ \\
Degrees of freedom & 2 \\
Lifting distance of cutting tool $(\mathrm{mm})$ & $-5 \sim 15$ \\
\hline
\end{tabular}

\section{CONCLUSIONS}

Apermanent magnet adsorbed repairing end effector is developed. Equipped withawall-climbing robot, tasks like allposition amendingor reshaping of weld seam may be carried out on complex curved surface of some steel structures, such as penstock, spiral case, turbine runner in large hydropower stations.

When the cutting tool is fixing in 2D cutting force mode, requirement of driving force is decreased to reduce structure stiffness and powerconsumption for manipulatorparallel to workpiece surface.

Reliable adsorption, flexible movement and curved surface adaptation are realized with the specially designed PMASA. The total size of the prototypical REE is $\Phi 274 \mathrm{~mm} \times 240 \mathrm{~mm}$ and total weight is less than $10 \mathrm{~kg}$. Cutting tool can be lifted and rotated in two degrees of freedom. Curved surface with curvature radius above $1.5 \mathrm{~m}$ could be adapted. 


\section{REFERENCES}

[1] Hazel, B.,Côté, J.,Laroche, Y., et al.,A portable, multiprocess, trackbased robot for in situ work on hydropower equipment.Journal of Field Robotics, 29(1), pp. 69-101, 2012.

[2] Chen, Q., Sun Z.G.,ZhangW.Z.,etal.,A robot for welding repair of hydraulic turbine blade.2008 IEEE International Conference on Robotics, Automation and Mechatronics, RAM 2008,pp. 155-159, 2008.

[3] Simas, H.,Golin, J.F.,Pieri, E.R.D.,et al., Development of an automated system for cavitation repairing in rotors of large hydroelectric plants. 2012 2nd Int. Conf. on Applied Robotics for the Power Industry, pp. 39-44, 2012.

[4] Cui, Z.W., Chen, Y.H., Sun Z.G., et al., Self-adaptive wall-climbing robot employing multi-body permanent magnetic adhesion system. Chinese Patent ZL201010539365.3. 2012 (in Chinese).

[5] Wang, G.L., Wang, Y.Q., Zhang, L., et al., Development and Polishing Process of a Mobile Robot Finishing Large Mold Surface.Machining Science and Technology, 18(4), pp. 603-625, 2014.

[6] Cui, Z.W., Sun, Z.G., Zhang, W.Z., et al., Efficient weld bead shaping method for a wall-climbing robot. Journal of Tsinghua University (Science and Technology), 54(9), pp. 1127-1130, 2014. 